\title{
MEET THE PROFESSOR SESSIONS
}

\section{Thursday, May 3, 2001}

MT1

Early Detection of Prostate Cancer: What's New

Michael Barry, MD, Chief, General Medicine Unit, Massachusetts General Hospital

MT2

Policy Issues For The Uninsured

Andrew Bindman, MD, Associate Professor, University of California - San Francisco

MT3

Inequality in Quality: Strategies for Reducing Socioeconomic, Racial, and Ethnic Disparities in Health Care

Carolyn Clancy, MD, Director, Center for Outcomes and Effectiveness Research, Agency for Healthcare

Research and Quality

MT4

Prevention of Breast Cancer in Primary Care: A New Approach

Steve Cummings, MD, Professor of Medicine, University of California - San Francisco

MT5

Couples In Medicine

Robert H. Fletcher, MD, MSc and Suzanne W. Fletcher, MD, Professors of Ambulatory Care and Prevention, Harvard Medical School

MT6

An Historical Perspective on Racial and Ethnic Health Disparities

Rodney G. Hood, MD, President, National Medical Association

MT7

Alternative Medicine

Ellen F. Hughes, MD, Associate Clinical Professor, University of California - San Francisco

MT8

Depression in Primary Care

Kurt Kroenke, MD, Professor of Medicine, Regenstrief Institute

MT9

Challenges Facing Academic Health Centers

Gerald S. Levey, MD, Provost and Dean, UCLA School of Medicine

MT10

Targeting Preventive Care in Underserved Populations

Stephen J. McPhee, MD, Professor of Medicine, University of California - San Francisco

MT11

National Institute of Mental Health Funding Opportunities for Research on Co-Morbid Mental and Medical Disorders

Peter Muehrer, PhD, Chief, Health and Behavioral Science Research Branch, Division of Mental Disorders, Behavior Research, and AIDS, National Institute of Mental Health, National Institutes of Health

MT12

Minority Faculty Development

Neil R. Powe, MD, MPH, MBA, Director, Welch Center for Prevention, Epidemiology and Clinical Research, Professor of Medicine, Epidemiology and Health Policy \& Management, The Johns Hopkins Medical Institutions 
MT13

Protecting Human Subjects in Medical Research - Where is the Health Services Research Voice?

Lisa V. Rubenstein, MD, MSPH, Professor of Medicine, VA Greater Los Angeles and UCLA

MT14

Research on Disparities in Health: Policy Relevant or Subversive?

Martin Shapiro, MD, PhD, Chief, General Internal Medicine and Health Services Research, UCLA School of Medicine

MT15

Challenges in Contemporary Medical Teaching: Areas for Attention

Kelley M. Skeff, MD, PhD, Professor of Medicine, Principal Investigator, Stanford Faculty Development Program, Internal Medicine Residency Program Director, Stanford University Medical Center

\section{Friday, May 4, 2001}

MF1

Peer Review in the Electronic Age

Eric Bass, MD, MPH, Editor, Journal of General Internal Medicine and Trish Groves, MBBS, MRCPsych, Primary

Care Editor, British Medical Journal

MF2

Identifying and Eliminating Disparities in Health: A Policy-based Approach

David M. Carlisle, MD, PhD, Director, Office of Statewide (California) Health Planning and Development

MF3

The Role of General Internists in National Health Policy

John Eisenberg, MD, Director, Agency for Healthcare Research and Quality

MF4

Health Care For the Homeless - Community-Based Care

Susan Fleischman, MD, Medical Director, Venice Family Clinic

MF5

What You Should Ask from Your Department Chairman

Lee Goldman, MD, MPH, Chairman, Department of Medicine, University of California - San Francisco

MF6

The Implication of Recent Clinical Trials for Use of Postmenopausal Hormone Therapy

Deborah Grady, MD, MPH, Professor of Epidemiology and of Medicine, University of California - San Francisco

MF7

Clinical Update in Diabetes

Rodney A. Hayward, MD, Director, VA Center for Health Service Research and Development Center, Ann Arbor

VAMC, Professor of Medicine and Public Health, University of Michigan

MF8

A Gaijin Under The Ginkos: Consulting On Curriculum Change Across Cultures

Thomas S. Inui, ScM, MD, President and CEO, Fetzer Institute

MF9

Update on Evaluation and Management of Syncope

Wishwa N. Kapoor, MD, Chief, Division of General Medicine, University of Pittsburgh Medical School 
MF 10

Principles and Pragmatism: Issues in Composing a Career in General Internal Medicine

C. Seth Landefeld, MD, Professor of Medicine and Chief, Division of Geriatrics, San Francisco VAMC

MF 11

The Role of Medical Director as an Opportunity for Applied Research and Development

Thomas H. Lee, MD, Medical Director, Brigham and Women's Hospital

MF 12

Clinician-Educators

Wendy Levinson, MD, Director, RWJ Clinical Scholars Program, University of Chicago

MF 13

Health Disparities in America: What Can Public - Private Partnerships Accomplish?

Nicole Lurie, MD, Former Principal Deputy Assistant Secretary for Health

MF 14

Smoking Cessation

Nancy A. Rigotti, MD, Associate Professor, Massachusetts General Hospital, Harvard Medical School

MF 15

Teaching Cross-Cultural Communication and Cultural Competence in Health Care

Melissa Welch, MD, Chief Medical Officer, Community Health Network of San Francisco

\section{Accreditation}

The Society of General Internal Medicine is accredited by the Accreditation Council for Continuing Medical Education (ACCME) to sponsor continuing medical education for physicians. The Society of General Internal Medicine takes responsibility for the content, quality, and scientific integrity of this CME activity.

\section{Credit Designation}

The Society of General Internal Medicine designates continuing medical education activity credits in Category 1 of the AMA Physician's Recognition Award as follows:

Full Day Precourses: 6.5 hours

Half Day Precourses: 3 hours

Annual Meeting up to 21.5 hours

Physicians must complete and return an application for CME hours, identifying the specific sessions that $\mathrm{s} /$ he actually attended. 